\title{
Wet Chemical Controllable Synthesis of Hematite Ellipsoids with Structurally Enhanced Visible Light Property
}

\author{
Chengliang Han, ${ }^{1,2}$ Jie Han, ${ }^{1}$ Qiankun $\mathrm{Li}^{1}{ }^{1}$ and Jingsong Xie ${ }^{1}$ \\ ${ }^{1}$ Department of Chemical and Material Engineering, Hefei University, Hefei 230601, China \\ ${ }^{2}$ Institute of Solid State Physics, Chinese Academy of Sciences, Hefei 230031, China \\ Correspondence should be addressed to Chengliang Han; clhan@issp.ac.cn
}

Received 4 August 2013; Accepted 5 September 2013

Academic Editors: K. Prokeš and D. Zhang

Copyright (C) 2013 Chengliang Han et al. This is an open access article distributed under the Creative Commons Attribution License, which permits unrestricted use, distribution, and reproduction in any medium, provided the original work is properly cited.

\begin{abstract}
A facile and economic route has been presented for mass production of micro/nanostructured hematite microcrystals based on the wet chemical controllable method. The as-prepared samples were characterized using X-ray diffraction, scanning electron microscopy, transmission electron microscopy, and UV-Vis absorption spectroscopy. The results showed that the product was mesoporous $\alpha-\mathrm{Fe}_{2} \mathrm{O}_{3}$ and nearly elliptical in shape. Each hematite ellipsoid was packed by many $\alpha-\mathrm{Fe}_{2} \mathrm{O}_{3}$ nanoparticles. The values of vapor pressure in reaction systems played vital roles in the formation of porous hematite ellipsoids. Optical tests demonstrated that the micro/nanostructured elliptical hematite exhibited enhanced visible light property at room temperature. The formation of these porous hematite ellipsoids could be attributed to the vapor pressure induced oriented assembling of lots of $\alpha$-Fe $\mathrm{O}_{3}$ nanoparticles.
\end{abstract}

\section{Introduction}

Hematite $\left(\alpha-\mathrm{Fe}_{2} \mathrm{O}_{3}\right)$ is the oldest known iron oxide mineral and is widely applied in catalysts, gas sensors, pigments, and promising photoanodes for solar cells [1-4]. Over the past ten years, various hematite nanostructures with a well-defined shape such as nanorods [5], nanowires [6], and nanobelts [7] have been obtained successfully by directional growth techniques [8-10], template guiding $[11,12]$, and decomposition of shape-regular iron precursors $[13,14]$. However, the previous reported shape-controllable synthetic methods have some limitations. For example, the used shape-controlling reagents such as some templates and surfactants are usually more expensive and hard to wash out. Additionally, solid reaction processes for $\alpha-\mathrm{Fe}_{2} \mathrm{O}_{3}$ may introduce some other iron oxide phases and release harmful gases for possible environmental pollution. Consequently, developing simple and economic methods for preparation of hematite nanomaterials as well as the modification of their sizes, morphology, and porosity has been intensively pursued not only for their fundamental scientific interest but also for many technological applications. This work presents a new method to produce large-scale
$\alpha-\mathrm{Fe}_{2} \mathrm{O}_{3}$ micro/nanostructured porous ellipsoids. The size and shape of as-prepared $\alpha-\mathrm{Fe}_{2} \mathrm{O}_{3}$ can be well controlled only by simply regulating the values of vapor pressure in reaction systems. The results reported in this paper mainly encompass the formation mechanism of porous $\alpha-\mathrm{Fe}_{2} \mathrm{O}_{3}$ with different morphologies and their corresponding visible light properties at room temperature.

\section{Materials and Methods}

2.1. Preparation of the Samples. The micro/nanostructured hematites were prepared as follows. Firstly, the $\mathrm{Fe}(\mathrm{OH})_{3}$ precursors were precipitated from $\mathrm{FeCl}_{3} \cdot 6 \mathrm{H}_{2} \mathrm{O}$ solution by adding proper ammonia $\left(\mathrm{NH}_{3} \cdot \mathrm{H}_{2} \mathrm{O}\right)$. And the above $\mathrm{Fe}(\mathrm{OH})_{3}$ with the solution was transferred into a $100 \mathrm{~mL}$ Teflon autoclave with a pressure gage for detecting internal vapor pressure. Then, the above sealed Teflon autoclave was heated to $453 \mathrm{~K}$, and the internal vapor pressure was kept under $1.45 \times 10^{5} \mathrm{~Pa}$ for $2 \mathrm{~h}$. After cooling to ambient temperature, the bright red powder was ultrasonically rinsed for several times in deionized water and ethanol, respectively. 


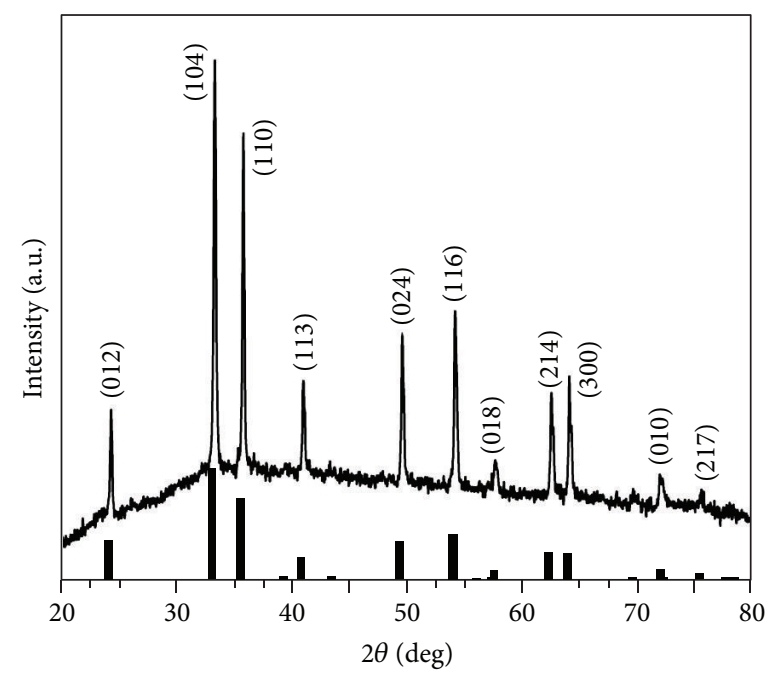

FIGURE 1: XRD patterns of the as-synthesized sample and standard $\alpha-\mathrm{Fe}_{2} \mathrm{O}_{3}$ powder (the line spectrum).
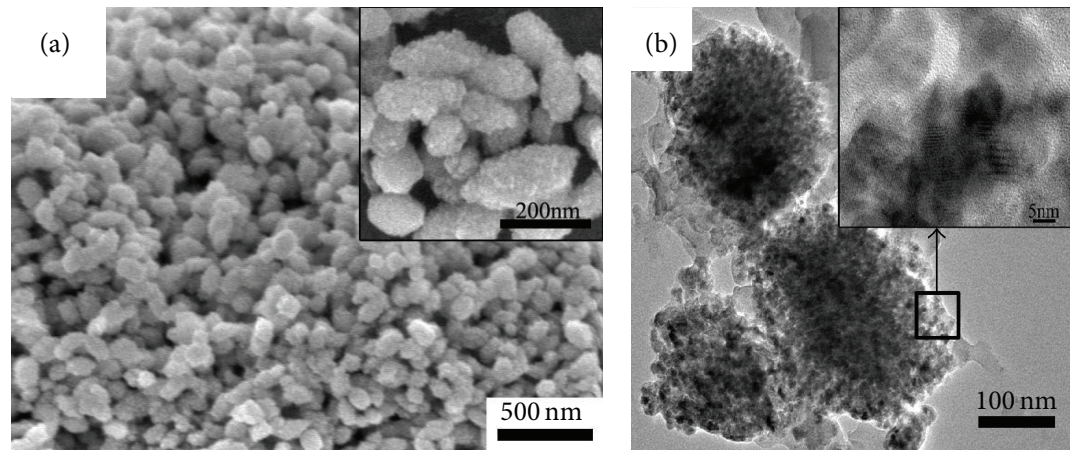

Figure 2: Microstructural examination of $\alpha-\mathrm{Fe}_{2} \mathrm{O}_{3}$ ellipsoids. (a) Low-magnification SEM image; (b) low-magnification TEM image (insets: corresponding high-magnification).

Finally, the sample was collected by a centrifuge and dried in a vacuum oven at $353 \mathrm{~K}$ for $6 \mathrm{~h}$.

2.2. Characterization of the Samples. X-ray powder diffraction (XRD) patterns were recorded on a Philips X'pert diffractometer using $\mathrm{CuK}_{\alpha}$ radiation $(\lambda=1.5419 \AA)$. Scanning electron microscopy (SEM) was recorded on a Sirion 200 FEI field emission scanning electron microscope. The transmission electron microscopic (TEM) micrographs were taken with a JEOL-2010 field emission transmission electron microscope with an accelerating voltage of $200 \mathrm{kV}$. The UVVis absorption spectra were taken on a spectrophotometer (Cary 5E UV-Vis-NIR) from 200 to $1200 \mathrm{~nm}$.

\section{Results and Discussion}

3.1. XRD and Morphology of As-Prepared Samples. After $\mathrm{Fe}(\mathrm{OH})_{3}$ precursors in solution were heated at $453 \mathrm{~K}$ for $2 \mathrm{~h}$ in Teflon autoclave with the internal vapor $1.45 \times 10^{5} \mathrm{~Pa}$ or so, the red powders were collected by a centrifuge. The corresponding X-ray diffraction (XRD) was illustrated in Figure 1. It can be found that all the diffraction peaks can be

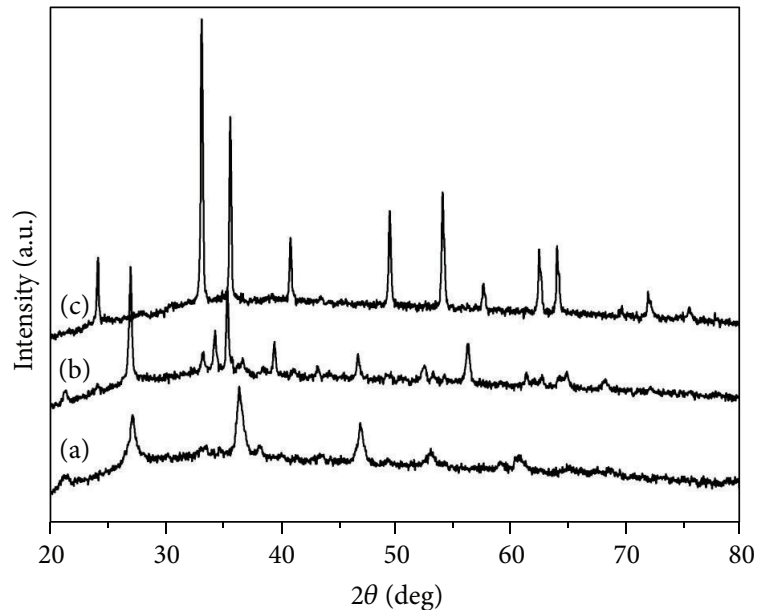

FIGURE 3: XRD patterns of samples under different pressures ((a) $1.02 \times 10^{5} \mathrm{~Pa}$ (b) $1.15 \times 10^{5} \mathrm{~Pa}$ (c) $1.62 \times 10^{5} \mathrm{~Pa}$ ).

indexed to pure $\alpha-\mathrm{Fe}_{2} \mathrm{O}_{3}$ (JCPDS NO. 89-2810). The intense peaks of the XRD pattern indicate that the as-prepared powders were well-crystallized $\alpha-\mathrm{Fe}_{2} \mathrm{O}_{3}$. 

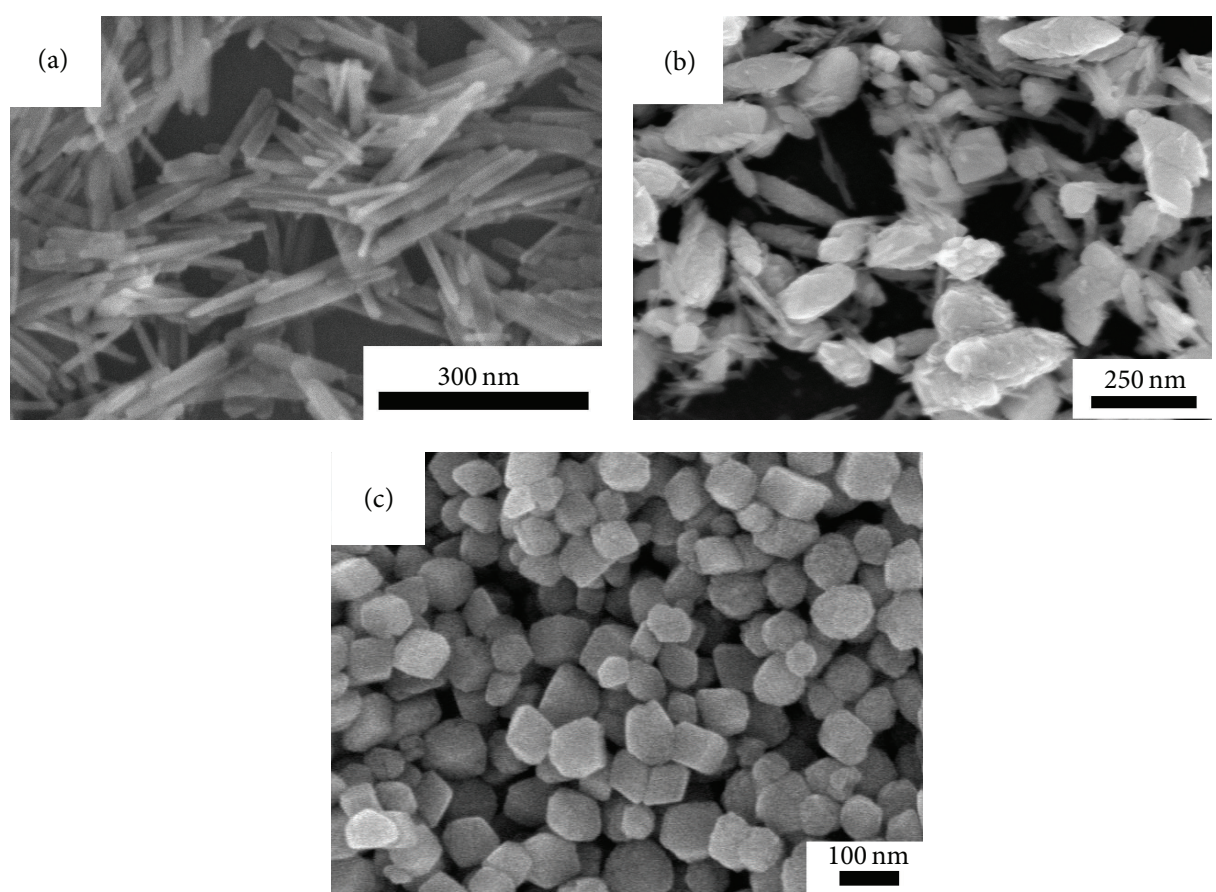

Figure 4: Morphology of samples at different pressures ((a) $1.02 \times 10^{5} \mathrm{~Pa}$, (b) $1.15 \times 10^{5} \mathrm{~Pa}$, and (c) $1.62 \times 10^{5} \mathrm{~Pa}$ ).

FE-SEM observations have shown that each as-prepared $\alpha-\mathrm{Fe}_{2} \mathrm{O}_{3}$ particle is of collective-like morphology with nearly elliptical in shape and nanoscaled surface roughness, as illustrated in Figure 2(a) and its inset. Each hematite ellipsoid is $500 \mathrm{~nm}$ and $120 \mathrm{~nm}$ in major and short axis, respectively (seen from Figure 2(a)). Further microstructural examination conducted for such $\alpha-\mathrm{Fe}_{2} \mathrm{O}_{3}$ ellipsoids was shown in Figure 2(b). It was confirmed that many $\alpha-\mathrm{Fe}_{2} \mathrm{O}_{3}$ nanoparticles $(\sim 20 \mathrm{~nm})$ reconstructed the porous hematite ellipsoid. The surface of every ellipsoid is also thus rough.

In general, the values of pressure in reaction systems will determine the chemical reaction start at the same reaction temperature. So different composition products can be gained under different values of pressures. Our deep and systematic studies have revealed that pure goethite $(\alpha$ $\mathrm{FeOOH}$ ) nanorods (seen from Figures 3(a) and 4(a)) will be obtained when the value of reactive pressure is less than $1.02 \times 10^{5} \mathrm{~Pa}$. And the mixture of $\alpha$-FeOOH nanorods and $\alpha$ $\mathrm{Fe}_{2} \mathrm{O}_{3}$ ellipsoids will be acquired when the value of pressure is between $1.15 \times 10^{5} \mathrm{~Pa}$ and $1.45 \times 10^{5} \mathrm{~Pa}$, as shown in Figures 3 (b) and 4(b), respectively.

3.2. Effect of Vapor Pressure. When the value of pressure is next to $1.62 \times 10^{5} \mathrm{~Pa}$ or higher, pure $\alpha-\mathrm{Fe}_{2} \mathrm{O}_{3}$ nanocrystals will be achieved (seen from Figure 3(c)). Hence, a lower value of reactive pressure was not beneficial to the formation of $\alpha-\mathrm{Fe}_{2} \mathrm{O}_{3}$. However, higher value of pressure will lead to lots of homogeneous $\alpha-\mathrm{Fe}_{2} \mathrm{O}_{3}$ solid quasicubic particles (seen from Figure $4(\mathrm{c})$ ) instead of the porous $\alpha-\mathrm{Fe}_{2} \mathrm{O}_{3}$ ellipsoids, as illustrated in Figure 2. Therefore, it can be concluded that the values of vapor pressure in reaction systems will influence not only the composition of the products but also the morphologies.

3.3. Formation of Porous $\alpha-\mathrm{Fe}_{2} \mathrm{O}_{3}$ Ellipsoids. The formation process of $\alpha-\mathrm{Fe}_{2} \mathrm{O}_{3}$ porous ellipsoids could be described in the following three stages. First of all, the $\mathrm{Fe}(\mathrm{OH})_{3}$ precursors would be formed by the precipitation between $\mathrm{Fe}^{3+}$ and $\mathrm{OH}^{-}$at room temperature (1). With subsequent heating at $453 \mathrm{~K}$, the $\mathrm{Fe}(\mathrm{OH})_{3}$ will begin to decompose into $\alpha$-FeOOH (2), which is finally dehydrated to $\alpha-\mathrm{Fe}_{2} \mathrm{O}_{3}$ molecules (3). Secondly, when the concentration of $\alpha-\mathrm{Fe}_{2} \mathrm{O}_{3}$ molecules was supersaturated, ultrafine $\alpha-\mathrm{Fe}_{2} \mathrm{O}_{3}$ particles would be formed in the solution by nucleation and growth:

$$
\begin{gathered}
\mathrm{Fe}^{3+}+3 \mathrm{OH}^{-} \stackrel{298 \mathrm{~K}}{\longrightarrow} \mathrm{Fe}(\mathrm{OH})_{3} \\
\mathrm{Fe}(\mathrm{OH})_{3} \stackrel{453 \mathrm{~K}}{\longrightarrow} \alpha-\mathrm{FeOOH}+\mathrm{H}_{2} \mathrm{O} \\
2 \alpha-\mathrm{FeOOH} \stackrel{453 \mathrm{~K}}{\longrightarrow} \alpha-\mathrm{Fe}_{2} \mathrm{O}_{3}+2 \mathrm{H}_{2} \mathrm{O}
\end{gathered}
$$

Finally, the as-formed hematite nanoparticles would be further coarsened by an oriented-assembling mode in order to reduce the surface energy of $\alpha-\mathrm{Fe}_{2} \mathrm{O}_{3}$ particles which were polar crystals and tended to spontaneously assemble $[15,16]$. The proper value of vapor pressure will help $\alpha-\mathrm{Fe}_{2} \mathrm{O}_{3}$ nanocrystals migrate and readjust more easily in a reactor. As a result, with the assemble going on, the porous hematite ellipsoid packed with many $\alpha-\mathrm{Fe}_{2} \mathrm{O}_{3}$ nanoparticles would be formed. The above three stages have been illustrated in Figure 5. We acknowledge that the true formation mechanism of porous $\alpha-\mathrm{Fe}_{2} \mathrm{O}_{3}$ elliptical structures is still unclear. 


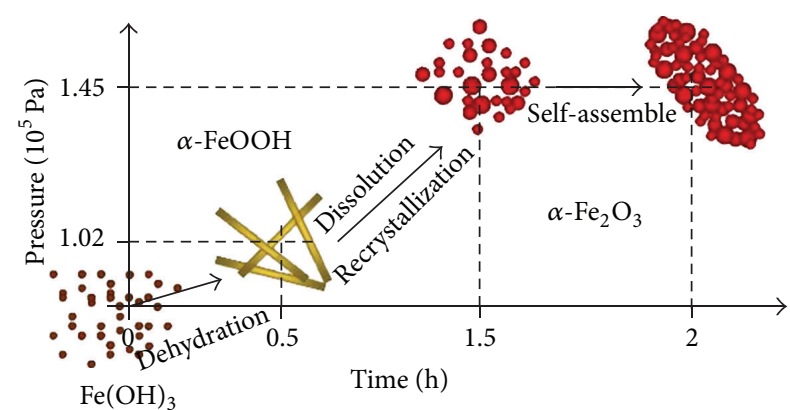

Figure 5: Schematic illustration for formation of porous $\alpha-\mathrm{Fe}_{2} \mathrm{O}_{3}$ ellipsoids.

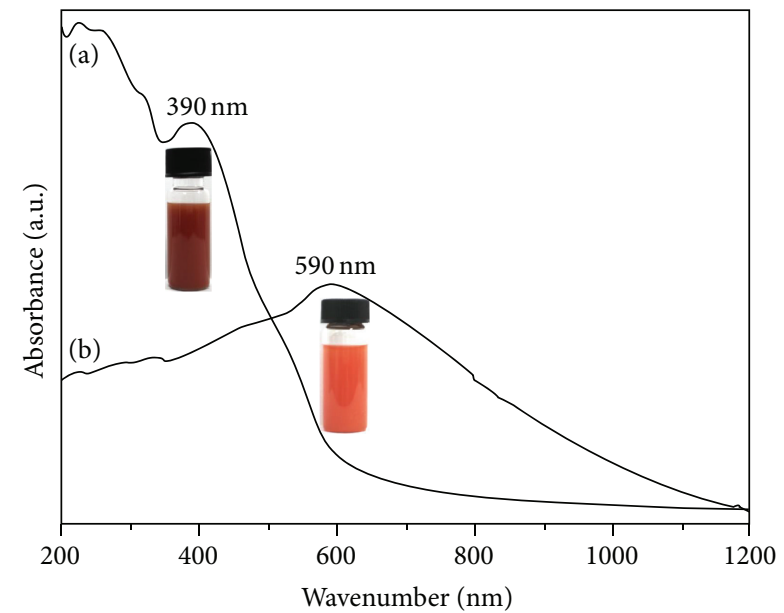

FIGURE 6: UV-Vis spectrums of $\alpha-\mathrm{Fe}_{2} \mathrm{O}_{3}$ from various pressures: (a) $1.62 \times 10^{5} \mathrm{~Pa}$; (b) $1.45 \times 10^{5} \mathrm{~Pa}$.

However, it is obvious that the values of vapor pressure in a reactor are of great importance in the growth of porous $\alpha$ $\mathrm{Fe}_{2} \mathrm{O}_{3}$ ellipsoids.

3.4. Ultraviolet Visible Optical Properties. The optical absorption measurement of as-prepared $\alpha-\mathrm{Fe}_{2} \mathrm{O}_{3}$ products was conducted at room temperature, which may help the understanding of the electronic structure and size effect.

Figure 6(a) shows the optical absorption spectrum of the quasicubic $\alpha-\mathrm{Fe}_{2} \mathrm{O}_{3}$ nanostructures, and the optical absorption feature was observed at wavelength around $390 \mathrm{~nm}$ $(3.18 \mathrm{eV})$ and had an inflection and shift to the short wavelength compared to that reported by Li et al. [17]. Figure 6(b) shows the optical absorption spectrum of the ellipsoid-like micro/nanostructured $\alpha-\mathrm{Fe}_{2} \mathrm{O}_{3}$, and the absorption peak is about $590 \mathrm{~nm}(2.10 \mathrm{eV})$. The different optical adsorption properties of two different shaped $\alpha-\mathrm{Fe}_{2} \mathrm{O}_{3}$ can be attributed to their different structures. In a word, the as-obtained porous $\alpha-\mathrm{Fe}_{2} \mathrm{O}_{3}$ ellipsoids were extended for potential application in photodegradating pollutants under visible light. The relative studies are our next work.

\section{Conclusions}

In conclusion, we have demonstrated mass production of micro/nanostructured elliptical hematite by a wet chemical pressure-controlled method. Our investigations have showed that the values of vapor pressure in reaction systems have been considered to play vital roles in the formation of porous $\alpha-\mathrm{Fe}_{2} \mathrm{O}_{3}$ ellipsoids. The vapor pressure induced oriented assembling mechanism of polar hematite nanocrystals has been inferred. Importantly, the micro/nanostructured porous $\alpha-\mathrm{Fe}_{2} \mathrm{O}_{3}$ ellipsoids with excellent visible light property can be used as a novel potential photocatalyst for removal of some toxic chemicals.

\section{Acknowledgments}

The authors wish to acknowledge with thanks the support of this research by the National College Students' Innovation and Entrepreneurship Training and Practice of Foundation of Hefei University (Grant no. 201211059008), Natural Science Foundation of Education Department of Anhui Province (Grant no. KJ2012B148), Natural Science Foundation of Hefei University (Grant no. 13RC09), and Anhui Provincial Natural Science Foundation (Grant no. 1308085QB35).

\section{References}

[1] E. Thimsen, F. Le Formal, M. Grätzel, and S. C. Warren, "Influence of plasmonic Au nanoparticles on the photoactivity of $\mathrm{Fe}_{2} \mathrm{O}_{3}$ electrodes for water splitting," Nano Letters, vol. 11, no. 1, pp. 35-43, 2011.

[2] F. Nsib, N. Ayed, and Y. Chevalier, "Comparative study of the dispersion of three oxide pigments with sodium polymethacrylate dispersants in alkaline medium," Progress in Organic Coatings, vol. 60, no. 4, pp. 267-280, 2007.

[3] Y. Ling, G. Wang, D. A. Wheeler, J. Z. Zhang, and Y. Li, "Sndoped hematite nanostructures for photoelectrochemical water splitting," Nano Letters, vol. 11, no. 5, pp. 2119-2125, 2011.

[4] L. Yongmao, R. A. Paul, H. Adam, and C. Buddie M, " $\alpha$ $\mathrm{Fe}_{2} \mathrm{O}_{3}$ nanorods as anode material for lithium ion batteries," The Journal of Physical Chemistry Letters, vol. 2, no. 22, pp. 28852891, 2011.

[5] C. Wu, P. Yin, X. Zhu, C. OuYang, and Y. Xie, "Synthesis of hematite $\left(\alpha-\mathrm{Fe}_{2} \mathrm{O}_{3}\right)$ nanorods: diameter-size and shape effects on their applications in magnetism, lithium ion battery, and gas sensors," Journal of Physical Chemistry B, vol. 110, no. 36, pp. 17806-17812, 2006.

[6] R. M. Wang, Y. F. Chen, Y. Y. Fu, and H. Zhang, "Bicrystalline hematite nanowires," The Journal of Physical Chemistry B, vol. 109, no. 25, pp. 12245-12249, 2005.

[7] W. Xiaogang, W. Suhua, D. Yong, W. Zhonglin, and Y. Shihe, "Controlled growth of large-area, uniform, vertically aligned arrays of $\alpha-\mathrm{Fe}_{2} \mathrm{O}_{3}$ nanobelts and nanowires," The Journal of Physical Chemistry B, vol. 109, no. 1, pp. 215-220, 2005.

[8] L. Lili, C. Ying, L. Yang, and D. Lihong, "Template-free synthesis and photocatalytic properties of novel $\mathrm{Fe}_{2} \mathrm{O}_{3}$ hollow spheres," The Journal of Physical Chemistry C, vol. 111, no. 5, pp. 2123-2127, 2007.

[9] C.-J. Jia, L.-D. Sun, Z.-G. Yan et al., "Single-crystalline iron oxide nanotubes," Angewandte Chemie-International Edition, vol. 44, no. 28, pp. 4328-4333, 2005. 
[10] Z. Dengsong, D. Xianjun, S. Liyi, and G. Ruihua, "Shapecontrolled synthesis and catalytic application of ceria nanomaterials," Dalton Transactions, vol. 41, pp. 14455-14475, 2012.

[11] W. Xiaogang, W. Suhua, D. Yong, W. Zhonglin, and Y. Shihe, "Controlled growth of large-area, uniform, vertically aligned arrays of $\alpha-\mathrm{Fe}_{2} \mathrm{O}_{3}$ nanobelts and nanowires," The Journal of Physical Chemistry B, vol. 109, no. 1, pp. 215-220, 2005.

[12] Z. Sun, H. Yuan, Z. Liu, B. Han, and X. Zhang, "A highly efficient chemical sensor material for $\mathrm{H}_{2} \mathrm{~S}: \alpha-\mathrm{Fe}_{2} \mathrm{O}_{3}$ nanotubes fabricated using carbon nanotube templates," Advanced Materials, vol. 17, no. 24, pp. 2993-2997, 2005.

[13] L. Liu, H.-Z. Kou, W. Mo, H. Liu, and Y. Wang, "Surfactantassisted synthesis of $\alpha-\mathrm{Fe}_{2} \mathrm{O}_{3}$ nanotubes and nanorods with shape-dependent magnetic properties," Journal of Physical Chemistry B, vol. 110, no. 31, pp. 15218-15223, 2006.

[14] M. Chen, J. Jiang, X. Zhou, and G. Diao, "Preparation of akaganeite nanorods and their transformation to sphere shape hematite," Journal of Nanoscience and Nanotechnology, vol. 8, no. 8, pp. 3942-3948, 2008.

[15] L. Li, Y. Yu, F. Meng, Y. Tan, R. J. Hamers, and S. Jin, "Facile solution synthesis of $\alpha-\mathrm{FeF}_{3} \cdot 3 \mathrm{H}_{2} \mathrm{O}$ nanowires and their conversion to $\alpha-\mathrm{Fe}_{2} \mathrm{O}_{3}$ nanowires for photoelectrochemical application," Nano Letters, vol. 12, no. 2, pp. 724-731, 2012.

[16] J. Gu, S. Li, E. Wang et al., "Single-crystalline $\alpha-\mathrm{Fe}_{2} \mathrm{O}_{3}$ with hierarchical structures: controllable synthesis, formation mechanism and photocatalytic properties," Journal of Solid State Chemistry, vol. 182, no. 5, pp. 1265-1272, 2009.

[17] S. Li, H. Zhang, J. Wu, X. Ma, and D. Yang, "Shape-control fabrication and characterization of the airplane-like $\mathrm{FeO}(\mathrm{OH})$ and $\mathrm{Fe}_{2} \mathrm{O}_{3}$ nanostructures," Crystal Growth and Design, vol. 6, no. 2, pp. 351-353, 2006. 

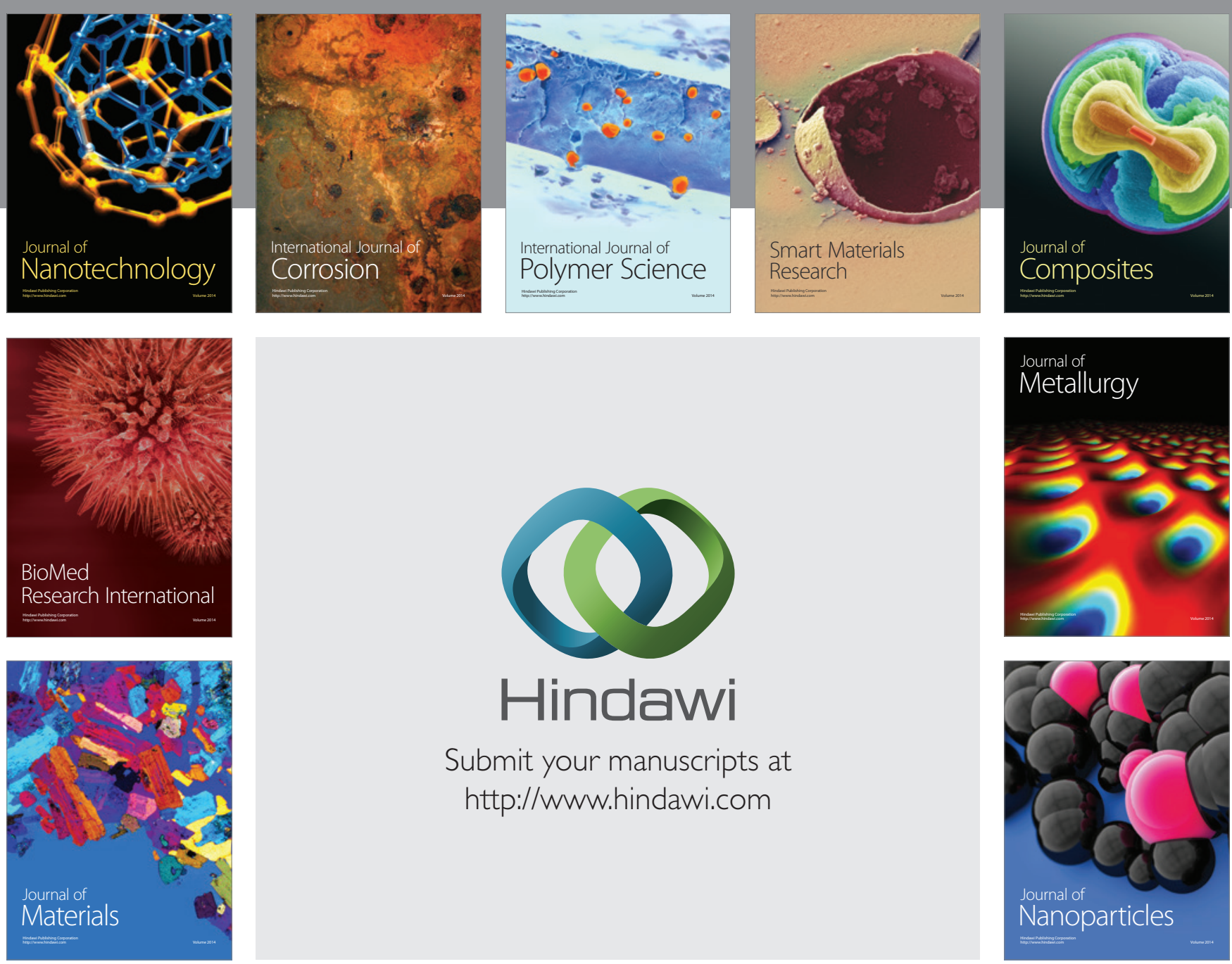

Submit your manuscripts at http://www.hindawi.com
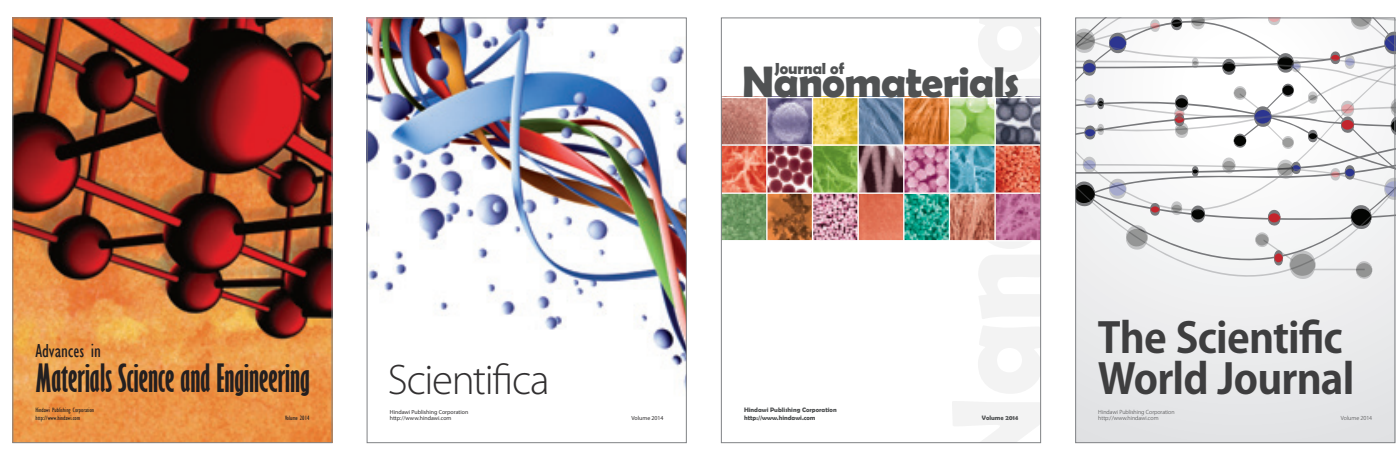

\section{The Scientific World Journal}
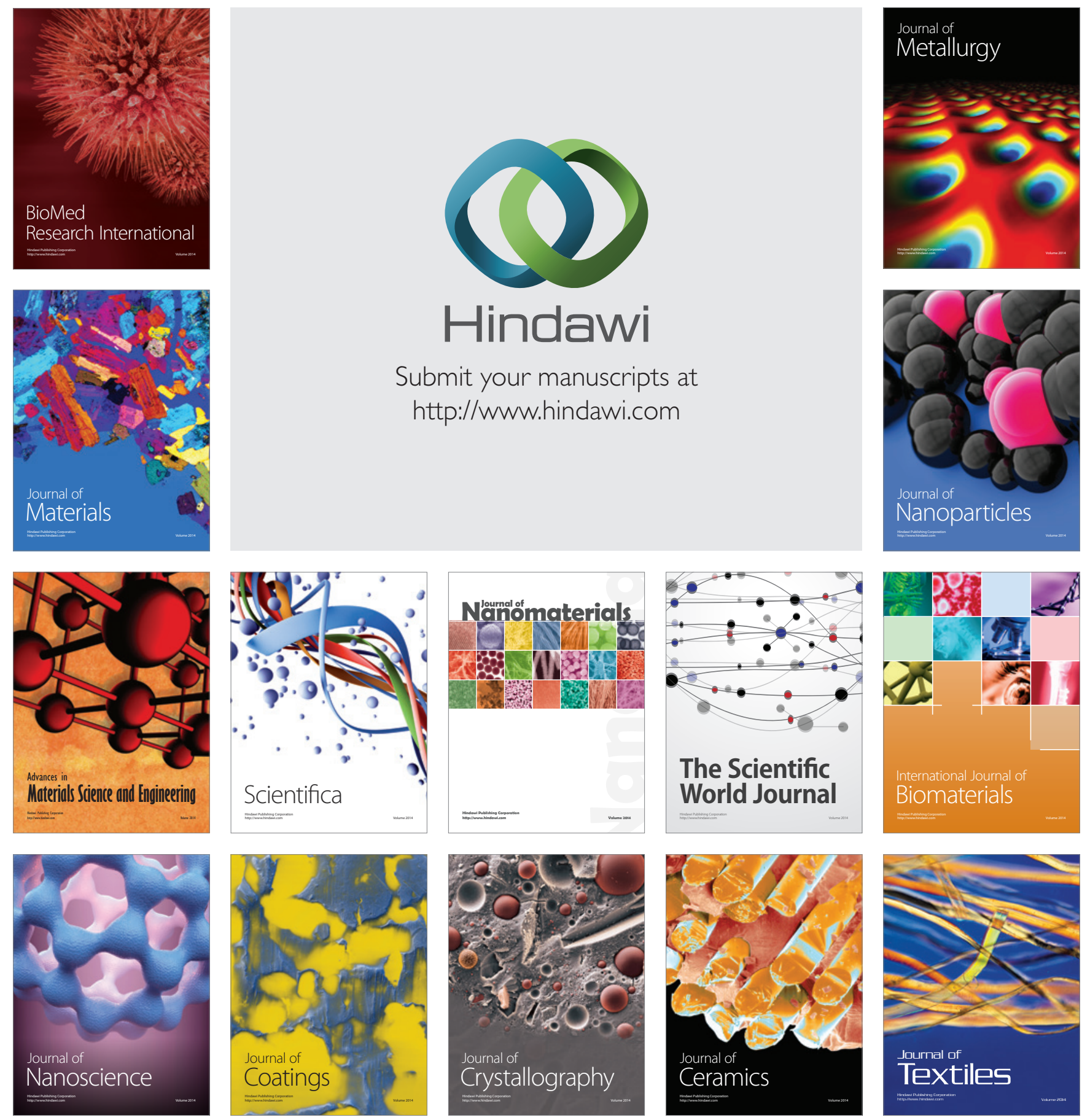